www.jmscr.igmpublication.org
Impact Factor 3.79

ISSN (e)-2347-176x

crossref DOI: http://dx.doi.org/10.18535/jmscr/v3i9.41

\title{
Incidence and Etiological Profiling of Acute Symptomatic Seizures in Western Uttar Pradesh
}

\author{
Authors \\ Malini Kulshrestha ${ }^{1}$, Gurpreet Singh ${ }^{2}$ and K K Dwivedi ${ }^{3}$ \\ ${ }^{1}$ Associate Professor, Dept of Medicine, Rohilkhand Medical College and Hospital, Bareilly U.P, India \\ Email:dr.malinik@gmail.com \\ ${ }^{2}$ Postgraduate Student Dept of Medicine, Rohilkhand Medical College and Hospital, Bareilly U.P India \\ Email: gurukalra@gmail.com \\ ${ }^{3}$ Professor and Head, Dept of Medicine, Rohilkhand Medical College and Hospital, Bareilly U.P India \\ Email: kkumadwivedi@hotmail.com
}

\begin{abstract}
An acute symptomatic seizure is defined as a clinical seizure occurring at the time of a systemic insult or in close temporal association with a documented brain insult (an acute medical or neurological illness). These etiologies may vary with time and place. This study was conducted with an aim to study the clinical profile of acute symptomatic seizures presenting to a tertiary care centre at North India.

All patients admitted in medicine wards with recent onset seizure either alone or in association with some medical complaints were considered in the study. Detailed history, neurological examination and baseline investigations were done in all the patients. Cerebrospinal fluid (CSF) analysis was done wherever indicated and CT scan / MRI brain were carried out. EEG was done within 48 hours of seizure (if the condition of patient permitted). Total number of patients was 47 (27 male: 20 female). Majority of patients were less than 40 years $(n=32)$ and most common presentation was single seizure $(n=24,51.1 \%)$. Status Epilepticus was seen in $(n=12,25.5 \%)$. Thirty cases had generalized tonic clonic seizures and 17 had partial seizure. CNS infections was the most common etiology $(n=44.7 \%)$ neurocysticercosis being the commonest (14/47; 31\%) followed by metabolic causes $(n=10 ; 21.3 \%)$, post stroke epilepsy $(7 / 47 ; 14.90 \%)$ and brain tumor $(3 / 47 ; 6.3 \%)$. Three had non specific gliosis. Outcome was good in cases with single seizure. Four patients who had status epilepticus expired.
\end{abstract}

Keywords: acute symptomtic seizures, etiology, incidence, outcome

\section{Introduction}

A seizure is a sudden surge of electrical activity in the brain. It may be a presenting feature of any medical or neurological disorder. The classification of seizures and that of the epilepsies is constantly being modified. In one of the latest versions, called as 'syndromic classification'- an attempt has been made to incorporate all of the seizure types and epileptic syndromes and to categorize them not only as partial and generalized but also according to their age of onset, their primary or secondary nature, the evidence of cortical loci of the epileptogenic lesions and the many clinical settings in which they occur ${ }^{[1]}$. 
An acute symptomatic seizure has been defined as a clinical seizure occurring at the time of a systemic insult or in close temporal association with a documented brain insult-an acute medical or neurological illness ${ }^{[1]}$. Suggestions have been made to define acute symptomatic seizures as those events occurring within 1 week of stroke, traumatic brain injury, anoxic encephalopathy, or intracranial surgery; at first identification of subdural hematoma; at the presence of an active central nervous system (CNS) infection; or during an active phase of multiple sclerosis or other autoimmune diseases. In addition, a diagnosis of acute symptomatic seizure should be made in the presence of severe metabolic derangements (documented within $24 \mathrm{hr}$ by specific biochemical or hematologic abnormalities), drug or alcohol intoxication and withdrawal, or exposure to welldefined epileptogenic drugs ${ }^{[2]}$. Around $40 \%$ of newly diagnosed seizures belong to this category ${ }^{[2],[3]}$. Differentiating characteristics of these seizures with regard to true epileptic disorders are (i) a clearly identified causal association, (ii) generally tend not to recur, and (iii) usually longterm anti-epileptic treatment is not necessary ${ }^{[3]}$. The risk of subsequent epilepsy is increased in a subgroup of these patients, especially in cases with associated cerebrovascular disorders, head injuries and central nervous system infections but not with metabolic disorders. Long-term preventive treatment is rarely indicated in the patients with metabolic disorders ${ }^{[3],[4]}$.

Though the incidences of acute symptomatic seizures have been reported in three studies viz. from Rochester (Minnesota), UK and South India as 3.1, 21 and $22.5 \%$ respectively ${ }^{[5],[6],[7]}$ however those on the mortality of acute symptomatic seizures are still lacking. A standardized mortality ratio (SMR) in patients with a newly diagnosed unprovoked seizure ranged from 2.5 to 4.1 based on different study population and design. The SMR was highest in the youngest patients as well as in patients with symptomatic seizures ${ }^{[3],[7]}$ and their etiological profile varied according to the place and period of study.

Owing to dearth of information on hospital based studies on clinical profile of such acute symptomatic seizures from north India, this study was taken up to ascertain the etiology of acute symptomatic seizures and its outcome.

\section{Material and Methods}

This was a prospective study conducted during January 2014- June 2015 at a medical college in western Uttar Pradesh. All the patients above 16 years, who came with first seizures in their life, were included in the study. The etiology of SE was classified as (i) acute symptomatic SEoccurring in patients with an acute medical or neurological illness, (ii) remote symptomatic SE owing to conditions resulting in a static encephalopathy or an antecedent insult such as stroke, head injury scars, calcifications, and (iii) cryptogenic- SE owing to conditions presumed to be symptomatic, whose cause is unclear ${ }^{[1]}$.

Cases of eclempsia, pseudoseizure and syncope were excluded by detailed history from an eye witness and clinical examination of the patients. The patients were classified and seizure frequency was noted. The seizures were classified according to definition by ILAE Commission Report into (i) single seizure- a brief seizure not followed by another, (ii) status epilepticus (SE) - (a) a continuous seizure of more than 5 minute duration or (b) two or more discrete seizures of five minutes duration between which there is incomplete recovery of consciousness and (iii) seizure cluster- the cluster of seizures that occur within a short period of time but do not meet the criteria for diagnosis of status.

All the patients with SE and seizure cluster were treated with intravenous diazepam and phenytoin according to the protocol- intravenous diazepam $(0.15 \mathrm{mg} / \mathrm{kg})$ followed by intravenous loading of phenytoin $(20 \mathrm{mg} / \mathrm{kg})$ as first-line drug treatment. If seizure did not stop within 30 min of starting of loading dose of phenytoin, patients were given 
additional intravenous phenytoin $(5 \mathrm{mg} / \mathrm{kg})$. The second line drugs were given when no response was observed with above drugs in first hour. Second line drugs were-intravenous loading dose of valproate $(25-30 \mathrm{mg} / \mathrm{kg}$ ) or phenobarbitone (20 $\mathrm{mg} / \mathrm{kg}$ ) as loading dose followed by maintenance drip $(60 \mathrm{mg} / \mathrm{min})$ till the control of seizures or one hour which ever was earlier. If the seizures could still not be controlled after one hour (refractory seizures), thiopentone $(10-20 \mathrm{mg} / \mathrm{kg})$ - loading dose followed by infusion $(0.5-1.0 \mathrm{mg} / \mathrm{kg} / \mathrm{hr})$ was given along with mechanical ventilatory support. The patients with single seizure were investigated first before AED was started.

The investigations like blood sugar, electrolytes including calcium, blood urea, serum creatinine, liver function test (LFT), complete hemogram including ESR were done on all the patients. Specific investigations where ever indicated viz. CT scan/ MRI brain - plain and contrast, electroencephalography(EEG), cerebrospinal fluid (CSF) analysis, electrocardiograph, X-ray - Chest (PA), serum anticysticercal antibodies, Mantoux and serum anti tubercular antibodies were done where ever indicated to reach the diagnosis.Those patients, in whom metabolic derangements were found, were given specific treatment. If seizure reoccurred in hospital stay then only AED administration was started. Response to AED and outcome was noted.

\section{Results}

The total number of patients included in this study was 47 (27 males and 20 females). Two third of patients were younger and attributed to less than 40 years $(n=32$; Table 1$)$.

The most predominant presentation was observed to be 'single seizure' that occurred in half of the population of patients $(n=24 ; 51.1 \%)$. Status epilepticus was seen in one quarter of the patients $(\mathrm{n}=12 ; 25.5 \%)$ and similar proportion was observed in seizure cluster $(\mathrm{n}=11 ; 23 \%)$.
Table 1. Distribution of cases of acute symptomatic seizures with respect to age and sex

\begin{tabular}{|l|c|c|c|}
\hline Age(Years) & Male & Female & Total (\%) \\
\hline $16-20$ & 6 & 3 & $9(19)$ \\
\hline $21-30$ & 7 & 3 & $10(21)$ \\
\hline $31-40$ & 6 & 7 & $13(28)$ \\
\hline $41-50$ & 4 & 1 & $5(11)$ \\
\hline $51-60$ & 3 & 4 & $7(15)$ \\
\hline $61-70$ & 1 & 0 & $1(2)$ \\
\hline $71-80$ & 0 & 2 & $2(4)$ \\
\hline Total & $\mathbf{2 7}$ & $\mathbf{2 0}$ & $\mathbf{4 7 ( 1 0 0 )}$ \\
\hline
\end{tabular}

Generalized tonic clonic seizures were present in 30patients whereas partial seizures were only observed in 17 patients.

CNS infections were found to be the most common etiology $(n=21 ; 45 \%)$ causing the acute seizures wherein the most prevalent infection was neurocysticercosis (NCC) which was observed in 30 per cent patients $(n=14)$. Most of the patients suffering from NCC had single seizure. The other infections observed were meningitis, tuberculoma and viral meningoencephalitis (Table 2). It was observed that the young adults (ie. $<40$ years) were most prone to CNS infections. Amongst the metabolic causes, CRF uremia $(n=6)$ as well as hypocalcemia $(n=4)$ were observed to be the most prevalent $(\mathrm{n}=10 ; 21 \%)$ causes of seizures (Table $3)$. 
Table 2. Etiological profile of seizures with reference to clinical presentation

\begin{tabular}{|c|c|c|c|c|}
\hline & Cases $(\%)$ & Single & Cluster & $\begin{array}{c}\text { Status } \\
\text { Epilepticus }\end{array}$ \\
\hline \multicolumn{5}{|l|}{$\begin{array}{l}\text { NEURO } \\
\text { INFECTION }\end{array}$} \\
\hline Neurocystisercosis & $14(29.8)$ & 11 & 2 & 1 \\
\hline Meningitis & $3(6.4)$ & 0 & 2 & 1 \\
\hline Encephalitis & $0(0.0)$ & 0 & 0 & 0 \\
\hline Meningo - Encephalitis & $2(4.3)$ & 0 & 2 & 0 \\
\hline Cerebral Malaria & $0(0.0)$ & 0 & 0 & 0 \\
\hline Tuberucloma & $2(4.3)$ & 2 & 0 & 0 \\
\hline Total & $21(44.7)$ & 13 & 6 & 2 \\
\hline \multicolumn{5}{|l|}{$\begin{array}{ll}\text { CEREBRO } & \text { VASCULAR } \\
\text { ACCIDENT } & \end{array}$} \\
\hline Infarct & $3(6.4)$ & 0 & 2 & 1 \\
\hline Haemorrhage & $4(8.5)$ & 0 & 0 & 4 \\
\hline Cortical Vein Thrombosis & $0(0.0)$ & 0 & 0 & 0 \\
\hline Total & 7 (14.9) & 0 & 2 & 5 \\
\hline \multicolumn{5}{|l|}{ METABOLIC DISORDERS } \\
\hline CRF (Uremia) & $4(8.5)$ & 2 & 0 & 2 \\
\hline Hyponatremia & $0(0.0)$ & 0 & 0 & 0 \\
\hline Hypocalcemia & $6(12.8)$ & 4 & 0 & 1 \\
\hline Hypoglycemia & $0(0.0)$ & 0 & 0 & 0 \\
\hline Total & $10(21.3)$ & 6 & 0 & 3 \\
\hline \multicolumn{5}{|l|}{ MISCELLANEOUS } \\
\hline Alcohol Withdrawal & $0(0.0)$ & 0 & 0 & 0 \\
\hline Poisoning & $2(4.3)$ & 0 & 1 & 1 \\
\hline Tumour/SOL & $3(6.4)$ & 1 & 2 & 0 \\
\hline Septicaemic Encephalopathy & $1(2.1)$ & 0 & 0 & 1 \\
\hline Gliosis & $3(6.4)$ & 3 & 0 & 0 \\
\hline Total & $9(19.1)$ & 4 & 3 & 2 \\
\hline GRAND TOTAL & $47(100.0)$ & 24 & 11 & 12 \\
\hline
\end{tabular}


Table 3. Etiological profile of seizures with respect to age of patients

\begin{tabular}{|c|c|c|c|c|c|c|c|c|}
\hline $\begin{array}{l}\text { ETIOLOGY OF SEIZURES IN AGE } \\
\text { GROUP }\end{array}$ & & 1 & 2 & 3 & 4 & 5 & 6 & 7 \\
\hline & $\mathrm{N}$ & $\begin{array}{l}16- \\
20 y r\end{array}$ & $\begin{array}{l}21- \\
30 y r\end{array}$ & $\begin{array}{l}31- \\
40 y r\end{array}$ & $\begin{array}{c}41- \\
50 \mathrm{yr}\end{array}$ & $\begin{array}{l}51- \\
60 \mathrm{yr}\end{array}$ & $\begin{array}{c}61- \\
70 y r\end{array}$ & $\begin{array}{l}\text { 71- } \\
80 y r\end{array}$ \\
\hline \multicolumn{9}{|l|}{ NEUROINFECTIONS } \\
\hline Neurocystisercosis & 14 & 2 & 3 & 6 & 2 & 1 & - & - \\
\hline Meningitis & 3 & 1 & - & 1 & 1 & - & - & - \\
\hline Encephalitis & - & - & - & - & - & - & - & - \\
\hline Meningo - Encephalitis & 2 & 1 & - & - & 1 & - & - & - \\
\hline Cerebral Malaria & - & - & - & - & - & - & - & - \\
\hline Tuberculoma & 2 & 1 & 1 & - & - & - & - & - \\
\hline Total & 21 & 5 & 4 & 7 & 4 & 1 & - & - \\
\hline \multicolumn{9}{|l|}{$\begin{array}{l}\text { CEREBRO VASCULAR ACCIDENT } \\
\text { (CVA) }\end{array}$} \\
\hline Infarct & 3 & - & - & - & 1 & 2 & - & - \\
\hline Haemorrhage & 4 & 1 & - & 2 & - & 1 & - & - \\
\hline Cortical Vein Thrombain & - & - & - & - & - & - & - & - \\
\hline Total & 7 & 1 & - & 2 & 1 & 3 & - & - \\
\hline METABOLIC & - & - & - & - & - & - & - & - \\
\hline CRF (Uremia) & 4 & 2 & - & 1 & - & 1 & - & - \\
\hline Hyponatremia & - & & - & - & - & - & - & - \\
\hline Hypocalcemia & 6 & 1 & - & 1 & - & 2 & - & - \\
\hline Hypoglycemia & - & - & - & - & - & - & - & - \\
\hline Total & 10 & 3 & 2 & 2 & - & 3 & - & - \\
\hline \multicolumn{9}{|l|}{ MISCELLONEOUS } \\
\hline Alcohal Withdrawal & - & - & - & - & - & - & - & - \\
\hline Poisoning & 2 & - & 1 & - & 1 & - & - & - \\
\hline Tumour/SOL & 3 & 1 & - & 1 & - & - & 1 & - \\
\hline Septicemic Encephalopathy & 1 & - & - & - & - & - & - & 1 \\
\hline Gliosis & 3 & - & 2 & 1 & - & - & - & - \\
\hline Total & 9 & 1 & 3 & 2 & 1 & - & 1 & 1 \\
\hline GRAND TOTAL & 47 & 10 & 9 & 13 & 6 & 7 & 1 & 1 \\
\hline
\end{tabular}

Cerebrovascular accident (CVA) accounted for seizure to the tune of $15 \%$ (Table 2) and was most frequent in the age group 51-60 (Table 3). Status epilepticus was frequent observation in hemorrhagic CVA. The brain tumor accounted for $6 \%$ seizures $(n=3)$. However the cause of seizures could not be ascertained in three patients due to non specific gliosis on MRI (Table2). Amongst group with metabolic etiology 2 patients required antiepileptics in hospital stay; when seizure recurred after 24 hours of treatment of specific cause. But later these drugs were tapered off and not used after 1 month.
Those with single seizures had good prognosis and they required single antiepileptic drug and there was no recurrence noted in the hospital stay however long term follow up could not be done. Half $(n=12)$ of those patients with seizure cluster and SE required two or more antiepileptic drugs to become seizure free and four of them succumbed to their illness during the hospital stay. The most frequent etiology amongst those who died was hemorrhagic CVA $(n=3)$ and one had viral meningoencephalitis. 


\section{Discussion}

This study was conducted at a teaching hospital in western Uttar Pradesh where most of the patients seeking treatment belong to rural background as well as lower or lower middle socio-economic status. Upon careful collection of records from January 2014 to June 2015, it was observed that 751 patients (out of 6750 medical admissions) suffered from seizure disorders. Patients $(n=47)$ with new onset of seizures were also observed accounting to
$6.26 \%$. The incidence and etiological profile of patients was found to be comparable with other such studies conducted in India (table 3). Our observations on high prevalence of neurological infections and neurocysticercosis (NCC) were similar to observations made in other studies in India (Table 4). However, the incidence of acute symptomatic seizures varied from 2.1 to $22.5 \%$ owing to difference in the population under study.

Table 4. Comparison of our findings with other studies from Indian subcontinent

\begin{tabular}{|c|c|c|c|c|c|}
\hline & Our findings & $\begin{array}{lr}\text { [7] } & \text { Murthy } \\
\text { and } & \text { Yanga } \\
(1999) & \end{array}$ & $\begin{array}{l}\text { [8] Narayanan } \\
\text { and Murthy } \\
(2007)\end{array}$ & $\begin{array}{l}\text { [9] Rao et. } \\
\text { al. (2015) }\end{array}$ & $\begin{array}{l}\text { [10] Sriharsha } \\
\text { and } \quad \text { Malali } \\
(2015)\end{array}$ \\
\hline Study design & $\begin{array}{l}\text { Prospective, } \\
\text { Medical } \\
\text { admissions in } \\
\text { a teaching } \\
\text { institute }\end{array}$ & $\begin{array}{l}\text { Prospective, } \\
\text { university } \\
\text { hospital in } \\
\text { south India on } \\
\text { all patients } \\
\text { with seizures }\end{array}$ & Neurology ICU & & $\begin{array}{l}\text { All new onset } \\
\text { seizure } \\
\text { including } \\
\text { pregnancy } \\
\text { related }\end{array}$ \\
\hline $\begin{array}{l}\text { Duration / } \\
\text { Population } \\
\text { studied }\end{array}$ & $\begin{array}{l}18 \text { month/ } \\
47 \quad \text { new } \\
\text { onsetseizure } \\
\text { Age>16yr o }\end{array}$ & $\begin{array}{l}\text { 1988-1994/ } \\
572 \text { patients }\end{array}$ & $\begin{array}{l}28 \text { month } \\
66 \text { patients }\end{array}$ & $\begin{array}{l}100 \text { patients } \\
\text { Age }>16 \text { yrs }\end{array}$ & 50 patients \\
\hline Incidence & $6.26 \%$ & $22.5 \%$ & $2.1 \%$ & - & - \\
\hline $\begin{array}{l}\text { Single /Status } \\
\text { epilepticus/ } \\
\text { Cluster }\end{array}$ & $\begin{array}{l}51 \% \text { single/ } \\
26 \% \text { SE } \\
23 \% \text { cluster }\end{array}$ & $\begin{array}{l}36 \% \text { single, } \\
16 \% \mathrm{SE}\end{array}$ & $\begin{array}{l}79 \% \text { single } \\
4 \% \mathrm{SE} \\
10 \% \text { cluster }\end{array}$ & - & - \\
\hline $\begin{array}{l}\text { Etiology- } \\
\text { metabolic }\end{array}$ & $21.3 \%$ & $8 \%$ & $32 \%$ & $12 \%$ & $10 \%$ \\
\hline $\begin{array}{l}\text { Neuroinfection } \\
\mathrm{s}\end{array}$ & $44.7 \%$ & $28 \%$ & $32 \%$ & $36 \%$ & $32 \%$ \\
\hline CVA & $14.9 \% \%$ & $14 \%$ & $21 \%$ & $25 \%$ & $26 \%$ \\
\hline outcome & $\begin{array}{l}4 \text { death SE } \\
\text { group }\end{array}$ & - & $\begin{array}{ll}2 \text { death } & \text { SE } \\
\text { group } & \end{array}$ & - & - \\
\hline
\end{tabular}

Generalized tonic clonic seizures were observed in 30 while partial seizure in 17 patients. Majority of the patients in all other studies mentioned above had a generalized presentation. Partial seizures are difficult to observe as they require experienced investigator as well as sincere and skillfully history recording. In our study, we observed that the most common occurrence was single seizure followed by status epilepticus. Various researchers have also reported NCC as the commonest cause of single seizure ${ }^{[7],[8],[9],[10]}$. In the present study, it was also noticed that the Neurocysticercosis $(29.8 \%)$ was the commonest cause of neurological infection, followed by meningitis $(6.4 \%)$ and tuberculoma (4.3\%). As Neurocysticercosis is endemic to India hence every new onset seizure must be evaluated by CT/MRI and serological confirmation, which has also been suggested by many workers ${ }^{[11],[12]}$. We also observed that the status epilepticus was in strong association with occurrence of hemorrhagic 
CVA (Table 2) and the patients suffering from it had a poor prognosis and very high mortality rate.

The etiological profile of the acute symptomatic seizures from north Indian region, were different from those of western countries. Neurological infections were more common as compared to CVA and need to be timely evaluated and treated in cases of adult onset seizure. Further, the acute symptomatic seizures should not be considered as a taboo as they have a good prognosis and do not need long term antiepileptic therapy.

\section{References}

1. Commission on Epidemiology and Prognosis of the ILAE-“Guidelines for epidemiological studies on epilepsy". Epilepsia 34 (4), pp592-6, 1993.

2. Beghi, E., Carpio, A., Forsgren, L., Hesdorffer, D.C., Malmgren Sander, J.W., Tomson, T. and Hauser, W.A. "Recommendation for a definition of acute symptomatic seizure". Epilepsia, 51 (4),pp 671-5,2010.

3. Mauri, L, Tejero-Juste, C., Escalza-Cortina, I., Jerico, I. and Morales Asin F. "Acute symptomatic epilepsies." Review Neurology.(article in Spanish) 31 (8), 77074,2000 .

4. Beleza, P. "Acute symptomatic seizures: a clinically oriented review". Neurologist., 18 (3), pp109-19,2012.

5. Annegers, J.F., Hauser, W.A., Lee, J.R.J. and Rocca, W "Incidence of acute symptomatic seizures in Rochester, Minnesota1935-1984”, Epilepsia, 36,pp 327-33,1995.

6. Sander, J.W.A.S., Hart, Y.M., Johnson, A.L. and Shorvon, S.D. "National General Practice Study of Epilepsy: newly diagnosed epileptic seizures in a general population." Lancet, 336, pp1267-71,1990.

7. Murthy, J.M.K and Yanga, R. "Acute symptomatic seizures - Incidence and etiological spectrum: a hospital-based study from South India." Seizure, 8, pp162165,1999 .

8. Narayanan, J.T. and Murthy, J.M. "Newonset acute symptomatic seizure in a neurological intensive care unit." Neurology India., 55 (2),pp 136-40,2007.

9. Rao, B.S., Vani, M.S. and Varma, G.A.R. "The study of etiological profile in new onset seizures in Indian scenario." International Journal of Advances in Medicine, 2 (1),pp 6-12,2015.

10. Sriharsha, K. and Malali, V. "Clinical and etiological study of seizures in young adults". Indian Journal of Basic and Applied Medical Research. 4 (2), pp76-83,2015.1

11. Sahu PS,Patros,JenaPK,SwainSK,DasBK. "Imaging and serological evidence of neurocysticercosis amongst patients with seizures in Odisha,An eastern coastal province in India." Journal of clinical and diagnostic research.9(5),pp06-10,2015.

12. Rajshekharan V,Raghava MV,Prabhakaran V,Omen A,Muliyil J.A"ctive epilepsy as an index burden of Neurocysticercosis in vellore district ,India”.Neurology, 67(12), pp2135-9,2006. 